\title{
A new performance indicator for acute myocardial infarction
}

\author{
R M Norris, on behalf of the Southern Heart Attack Response Project (SHARP) \\ Investigators *
}

\begin{abstract}
Objective-To develop a performance indicator for acute myocardial infarction which would reliably measure success of treatment and which might provide an alternative to case fatality as an audited outcome.

Design-A two year audit of all cases of acute myocardial infarction and resuscitated cases of out of hospital cardiac arrest from coronary heart disease in patients under 75 years of age. Behaviour of patients in calling for help, performance of the ambulance services in treating out of hospital arrest, and of the hospitals in providing resuscitation and thrombolytic treatment are audited separately.

Setting-Four district general hospitals.

Audited interventions-Resuscitation from cardiac arrest and thrombolytic treatment.

Main outcome measures-Hospital case fatality and lives saved/1000 patients treated.

Results-Overall, the lives of 83/1000 patients were saved (95\% confidence interval 70 to 96 ). Of these, 29 (35\%) were saved by out of hospital resuscitation and $38(46 \%)$ by in hospital resuscitation from cardiac arrest. It was estimated that 16 lives (19\%) were saved by thrombolytic treatment. There were no significant differences in case fatality among the hospitals.

Conclusions-Lives saved/1000 patients treated is an easily measurable index and assesses performance of the ambulance service as well as of the hospital. Because it is relatively insensitive to diagnostic definitions, it may provide a robust alternative to case fatality as a performance indicator.

(Heart 2001;85:395-401)
\end{abstract}

Keywords: acute myocardial infarction; audit; case fatality; outcome indicators

There is a growing perception that delivery of health care must be audited ${ }^{1}$ and outcome indicators for acute myocardial infarction have been proposed. ${ }^{2}{ }^{3}$ However, for any audit system to be meaningful, outcome measures must be unequivocal and as far as possible insensitive to variations in case mix and differences in diagnostic definitions.

The present two year study was carried out in four district general hospitals to establish a system for audit of acute myocardial infarction which was cost-effective and which might measure success of treatment as an outcome, in addition to case fatality. Data recorded were based on experience from the earlier UK heart attack study (UKHAS), ${ }^{4-6}$ but omitting patients who died outside hospital (recorded by UKHAS). Data from the in-hospital course were reduced to those items which, from the results of UKHAS, were found to be essential for reliable assessment of outcomes. In addition to the audit programme, a previously reported public educational campaign (Heart Attack Action! $)^{7}$ was extended during the second year of the study to the districts served by all four hospitals. Results of this latter project, which was aimed at reducing patient delay in calling for help, will be reported separately.

Correspondence to: Dr Norris

robin.norris@talk21.com

Accepted 8 November 2000

${ }^{\star} \mathrm{A}$ list of participating centres and investigators appears at the end of this report. nursing experience worked for one day a week. Another senior nurse acted as co-coordinator. Data collection started on 1 January 1997 in Brighton, on 1 April 1997 in the other hospitals, and finished on 31 March 1999 at all hospitals.

As in the earlier study, identification of cases was carried out by a combination of "hot" and "cold" pursuit, ${ }^{8}$ and events were recorded only in patients under 75 years of age. Cases of myocardial infarction showed at least two of the following three features: a typical or compatible clinical history; sequential ECG changes; and a rise in creatine kinase activity to at least twice the upper limit of normal for the hospital laboratory. Cases of out of hospital cardiac arrest were included if the cause was ischaemic heart disease and they survived with an independent cardiac output to reach hospital. Cases of myocardial infarction or sudden cardiac death occurring in patients who had been admitted for another reason, and had already been in hospital for 24 hours or more, were excluded. As a check on the completeness of inclusion, lists of patients in the appropriate age range with a coded diagnosis of acute myocardial infarction were obtained periodically from the clinical coding departments of the participating hospitals. Case notes of omitted patients were obtained and scrutinised for possible inclusion if study criteria were met. If study criteria were not met the cases were excluded, even though they had been coded as myocardial infarction. 
Selection of cases was thus without reference to the final diagnosis as recorded using the 10th revision of the International Classification of Diseases (ICD 10) by the hospitals' clinical coding department. In order to discover possible discrepancies between coding diagnoses and our own designation of acute myocardial infarction made using predefined criteria, we searched at one of the hospitals (hospital A) after completion of the study for study cases which had not been classified as acute myocardial infarction by clinical coding, and for coded cases not recorded by the study. This was achieved with the help of the information technology department using the hospital number and the computer operated patient administration system.

Data were recorded on standard forms at each hospital and entered on computer at the coordinating centre using a Paradox database. As in the previous study, we recorded the times of onset of symptoms, call for help, arrival of ambulance at home and at hospital, arrival in the coronary care unit or medical ward, administration of thrombolytic treatment (if given), and discharge from hospital or death. We also recorded details of the diagnostic ECG, whether or not the patient had cardiac failure (diagnosed clinically or radiologically), and the final diagnosis ( $Q$ wave or non- $Q$-wave infarction). For patients who had had a cardiac arrest, whether resuscitation was attempted or not, we recorded the date and time, place (out of hospital, ambulance, accident and emergency, coronary care unit, ward, or elsewhere in the hospital), the witness, the initial rhythm (if known), and survival or not from the initial resuscitation to the time of hospital discharge. Details of first arrests only were recorded. If the patient was resuscitated but later had a further cardiac arrest and died, resuscitation was deemed to have been unsuccessful.

Progress of the project was discussed at investigators' meetings which were held three to six monthly. Because we were aiming, through the public educational campaign, to bring patients under care more quickly, we analysed patient behaviour in calling for help from the ambulance service or from their general practitioner, and consequent delays in coming under care. We next examined ambulance performance in speed of response to the call and in bringing patients to hospital, and in the number of patients successfully resuscitated from out of hospital cardiac arrest. Finally we studied performance of hospitals in delivering both resuscitation from cardiac arrest and thrombolytic treatment.

Because lives saved/1000 patients treated is highly sensitive to delay ${ }^{5}$ and measures ambulance as well as hospital intervention, we used this as an alternative to case fatality as a performance indicator. As in the earlier study, we assumed that the lives of all hospital survivors from cardiac arrest had been saved by treatment. We used a figure of 30 lives saved/1000 patients treated ${ }^{9}$ as the measure of success of thrombolytic treatment; calculations based on delay in administration of thromboly$\operatorname{sis}^{10}$ gave almost identical results to the mean figure of 30/1000. The formula used for calculation of lives saved per 1000 treated was thus: ( $n$ successfully resuscitated $\times 1000 / n$ treated) + (proportion given thrombolytic treatment $\times$ 30).

Thus if $50 \%$ of patients received thrombolytic treatment, the number of lives saved by thrombolysis was $15 / 1000$. For the purpose of this report, we designate the four hospitals with their associated ambulance services A, B, C, and $\mathrm{D}$.

Comparisons were made using the $\chi^{2}$ test.

\section{Results}

We recorded 1759 cases, of which 640, 322, 405 , and 392 had been treated, respectively, at hospitals A, B, C, and D.

\section{PATIENT BEHAVIOUR}

In all, $81 \%$ of patients arrived at hospital by ambulance, and of these the majority called the ambulance directly (table 1). More patients did this in centre A than in the other centres $(63 \%$ v 50\%, 37\%, and 51\%; p < 0.001). Patients who called the ambulance directly came under ambulance care (median delay from symptom onset 1.2 hours $v 4.1$ hours) and arrived at hospital (median delay 1.7 hours $v 4.8$ hours) much more quickly than those who consulted their general practitioner before the ambulance was called. Surprisingly, however, patients in centre A, who were more likely than those in the other centres to call the ambulance directly, did not as a group come under ambulance care (median delay 1.6 hours $v 1.7,1.7$, and 1.6 hours) or hospital care (median delay 2.5 hours $v 2.5,2.6$, and 2.3 hours) earlier than those from the other centres. The main reason for the longer delay for patients calling their general practitioner was delay by the patients themselves in calling for help (data not shown). In particular, centre A patients who called their general practitioner appeared to have delayed much longer than the larger proportion who called their general practitioner from the other centres. The minority of patients who used their own transport arrived nearly as quickly (median 1.9 hours from symptom onset) as

Table 1 Effect of patient behaviour at the four centres

\begin{tabular}{|c|c|c|c|c|c|}
\hline & \multicolumn{4}{|c|}{ Centre } & \multirow[b]{2}{*}{ All } \\
\hline & $A$ & $B$ & $C$ & $D$ & \\
\hline Total cases & 640 & 322 & 405 & 392 & 1759 \\
\hline \multicolumn{6}{|l|}{ Transport to hospital } \\
\hline By ambulance (999 call) (\%) & 63 & 50 & 37 & 51 & 52 \\
\hline By ambulance (called GP first) (\%) & 19 & 36 & 40 & 28 & 29 \\
\hline Used own transport $(\%)$ & 18 & 14 & 23 & 21 & 19 \\
\hline \multirow{2}{*}{\multicolumn{6}{|c|}{ Median delay (hours) from symptom onset }} \\
\hline & & & & & \\
\hline All patients & 1.6 & 1.7 & 1.7 & 1.6 & 1.7 \\
\hline Called ambulance directly & 1.3 & 1.1 & 1.1 & 1.1 & 1.2 \\
\hline Called GP first & 5.8 & 4.2 & 3.0 & 3.9 & 4.1 \\
\hline \multicolumn{6}{|l|}{ To arrival at hospital } \\
\hline All patients & 2.5 & 2.5 & 2.6 & 2.3 & 2.5 \\
\hline Called ambulance directly & 1.8 & 1.7 & 1.7 & 1.7 & 1.7 \\
\hline Called GP first & 6.6 & 4.9 & 3.6 & 4.4 & 4.8 \\
\hline Used own transport & 2.9 & 1.5 & 2.0 & 2.2 & 1.9 \\
\hline \multicolumn{6}{|l|}{ Early arrival at hospital } \\
\hline Within 1 hour $(\%)$ & 18 & 16 & 13 & 13 & 15 \\
\hline Within 2 hours (\%) & 43 & 44 & 40 & 42 & 42 \\
\hline
\end{tabular}

GP, general practitioner. 
Table 2 Ambulance performance in treatment of out of hospital hospital cardic arrest

\begin{tabular}{llllll}
\hline & \multicolumn{2}{c}{ Service } & & \\
\cline { 2 - 5 } & $A$ & $B$ & $C$ & $D$ & All \\
\hline $\begin{array}{l}\text { No (\%) of patients transported following } \\
\quad \text { successful treatment of arrest }\end{array}$ & $38(7)$ & $18(6)$ & $17(5)$ & $5(2)^{\star \star \star}$ & $78(5)$ \\
$\begin{array}{l}\text { No (\%) of arrests witnessed by ambulance } \\
\text { personnel }\end{array}$ & $10(26)$ & $9(50)$ & $6(35)$ & $3(60)$ & $28(36)$ \\
$\begin{array}{l}\text { No (\%) of arrests not witnessed } \\
\text { No (\%) discharged from hospital }\end{array}$ & $28(74)$ & $9(50)$ & $11(65)$ & $2(40)$ & $50(64)$ \\
$\quad \begin{array}{lllll}\text { Witnessed arrests } \\
\text { Unwitnessed arrests }\end{array}$ & $9(90)$ & $7(78)$ & $5(83)$ & $3(100)$ & $24(86)$ \\
$\quad$ Total & $7(25)$ & $3(33)$ & $6(55)$ & $1(50)$ & $17(34)$ \\
\hline$\star \star \star$ p $<0.001$ vother services. & $16(42)$ & $10(56)$ & $11(65)$ & $4(80)$ & $41(53)$ \\
\hline
\end{tabular}

those who called the ambulance directly (median delay 1.7 hours). Only $15 \%$ of patients arrived at hospital within one hour of onset of symptoms and $42 \%$ within two hours of onset.

AMBULANCE SERVICE PERFORMANCE

Performance of the ambulance services in treating out of hospital cardiac arrest is compared in table 2. The proportions of patients successfully resuscitated are biased towards success, because patients who did not reach hospital alive were not included in the study. Overall, 78 patients $(5 \%$ of those who were transported by ambulance) had had restoration of cardiac output following a verified arrest, and in a little over one third of these the arrest had been witnessed by ambulance personnel. Fifty three per cent of these patients survived to be discharged from hospital, and success was more likely $(\mathrm{p}<0.001)$ for witnessed arrests $(86 \%)$ than for unwitnessed arrests (34\%). Significantly fewer cases of successfully resuscitated cardiac arrest were transported by ambulance service $\mathrm{D}$ than by the other services.

HOSPITAL PERFORMANCE

Case mix, incidence and outcomes from cardiac arrest, use of thrombolytic treatment,

Table 3 Comparison of hospital performance

\begin{tabular}{|c|c|c|c|c|c|}
\hline & \multicolumn{4}{|c|}{ Hospital } & \multirow[b]{2}{*}{ Total } \\
\hline & $A$ & $B$ & $C$ & $D$ & \\
\hline Total cases & 640 & 322 & 405 & 392 & 1759 \\
\hline $\begin{array}{l}\text { Case mix } \\
\text { Age (years) (mean (SD)) } \\
\text { Female }(\%) \\
\text { OOH arrest (\%) } \\
\text { LV failure }(\%)\end{array}$ & $\begin{array}{l}62(9) \\
24 \\
5.9 \\
23\end{array}$ & $\begin{array}{l}62(9) \\
29 \\
5.6 \\
18\end{array}$ & $\begin{array}{l}64(9) \\
28 \\
4.2 \\
25\end{array}$ & $\begin{array}{l}62(10) \\
27 \\
1.3^{\star \star \star} \\
20\end{array}$ & $\begin{array}{l}62(9) \\
26 \\
4.4 \\
22\end{array}$ \\
\hline $\begin{array}{l}\text { Cardiac arrest } \\
\text { Patients with first arrest in hospital (\%) } \\
\text { Resuscitation attempted (\%) } \\
\text { Arrests VF (\%) } \\
\text { Resuscitation successful (all rhythms) (\%) } \\
\text { Successful (VF) (\%) }\end{array}$ & $\begin{array}{l}12 \\
68 \\
34 \\
33 \\
62\end{array}$ & $\begin{array}{l}15 \\
76 \\
42 \\
45 \\
76\end{array}$ & $\begin{array}{l}12 \\
74 \\
34 \\
40 \\
88\end{array}$ & $\begin{array}{l}13 \\
74 \\
40 \\
43 \\
60\end{array}$ & $\begin{array}{l}13 \\
72 \\
37 \\
39 \\
70\end{array}$ \\
\hline $\begin{array}{l}\text { Thrombolytic treatment } \\
\text { Patients treated (\%) } \\
\text { Treated patients showing ST or LBBB (\%) } \\
\text { Median "door to needle" time (min) } \\
\text { Median "pain to needle" time (h) } \\
\text { Treated within } 1 \text { h of onset }(\%) \\
\text { Treated within } 2 \text { h of onset }(\%) \\
\text { "Call to needle" time } \leqslant 90 \text { min (\%) }\end{array}$ & $\begin{array}{l}53 \\
95 \\
45 \\
3.1 \\
3 \\
29 \\
54\end{array}$ & $\begin{array}{l}61 \\
96 \\
48 \\
3.3 \\
2 \\
18 \\
50\end{array}$ & $\begin{array}{l}48 \\
98 \\
58 \\
3.5 \\
1 \\
17 \\
39\end{array}$ & $\begin{array}{l}59 \\
88 \\
37 \\
3.0 \\
1 \\
26 \\
58\end{array}$ & $\begin{array}{l}55 \\
94 \\
45 \\
3.3 \\
2 \\
24 \\
51\end{array}$ \\
\hline $\begin{array}{l}\text { Case fatality (\%) } \\
\text { Including OOH arrests } \\
\text { Excluding OOH arrests }\end{array}$ & $\begin{array}{l}13.2 \\
10.5\end{array}$ & $\begin{array}{l}13.0 \\
11.0\end{array}$ & $\begin{array}{l}9.9 \\
8.9\end{array}$ & $\begin{array}{l}8.9 \\
8.7\end{array}$ & $\begin{array}{l}11.5 \\
9.8\end{array}$ \\
\hline
\end{tabular}

$\star \star \star \mathrm{p}<0.001 v$ other hospitals.

LBBB, left bundle branch block; LV, left ventricular; OOH, out of hospital; VF, ventricular fibrillation. and case fatality for the four hospitalstogether with the total results from all the hospitals - are shown in table 3. Indicators of case mix were similar at each of the hospitals except that hospital D recorded significantly fewer cases of out of hospital cardiac arrest $(1.3 \%)$ compared with the other hospitals $(5.9 \%, 5.6 \%$, and $4.2 \%)$. There was no significant difference among the hospitals in the proportion of patients who suffered a first cardiac arrest in hospital (overall 13\%), the proportion in whom resuscitation was attempted $(72 \%)$, or the proportion of arrests which were recorded to have been caused by ventricular fibrillation $(37 \%)$; neither was there any difference in the proportion of patients with arrest who were successfully resuscitated and discharged from hospital $39 \%$ of all treated arrests and $70 \%$ of arrests known to have been caused by ventricular fibrillation). Use of thrombolytic treatment was also similar (given to $55 \%$ of patients on average), as was the proportion of patients given thrombolysis who had the conventional ECG indications of ST elevation or left bundle branch block (94\%). The "door to needle" time (mean 45 minutes) was also not significantly different among the hospitals, although the door to needle time was less than $25 \%$ of the total pain to needle time (median 3.3 hours). Only $2 \%$ of the patients who were given thrombolytic treatment received it within the "golden hour" from the onset of symptoms, and $24 \%$ within two hours. Case fatality in hospital D (8.9\%) was lower than in hospital A $(13.2 \%)$, and this was of borderline significance $(\mathrm{p}<0.05)$. However, this difference became non-significant $(8.7 \% v 10.5 \%)$ when cases of out of hospital arrest were excluded.

Although indicators of case mix were similar at each of the hospitals (table 3), case mix had the expected powerful effect on case fatality (table 4). We considered age in the three decades of $<55$ years, 55-64 years, and 65-74 years. Fatality was more than three times as great in the highest than in the lowest age decade, and was significantly higher in women than in men in the lowest and highest decade. Left ventricular failure increased fatality nearly 10 -fold $(37 \% v 4 \%)$ and out of hospital resuscitation nearly fivefold ( $47 \%$ v $10 \%)$. However,

Table 4 Effect of case mix on hospital fatality

\begin{tabular}{|c|c|}
\hline Case mix variable & Hospital fatality (\%) \\
\hline \multicolumn{2}{|l|}{ Age and sex } \\
\hline \multicolumn{2}{|l|}{$<55$ years } \\
\hline Male & $11 / 325(3 \%)$ \\
\hline Female & $6 / 41(14 \%)^{\star \star}$ \\
\hline Male and female & $17 / 366(5 \%)$ \\
\hline \multicolumn{2}{|l|}{$55-64$ years } \\
\hline Male & $28 / 402(7 \%)$ \\
\hline Female & $10 / 120(8 \%)$ \\
\hline Male and female & $38 / 522(7 \%)$ \\
\hline \multicolumn{2}{|l|}{$65-74$ years } \\
\hline Male & $77 / 570(14 \%)$ \\
\hline Female & $70 / 304(23 \%)^{\star \star \star}$ \\
\hline Male and female & $147 / 874(17 \%)$ \\
\hline \multicolumn{2}{|l|}{ Left ventricular failure } \\
\hline Yes & $142 / 387(37 \%)$ \\
\hline No & $56 / 1367(4 \%)^{\star \star \star}$ \\
\hline \multicolumn{2}{|c|}{ Out of hospital resuscitation } \\
\hline Yes & $37 / 78(47 \%)$ \\
\hline No & $165 / 1681(10 \%)^{\star \star \star}$ \\
\hline
\end{tabular}




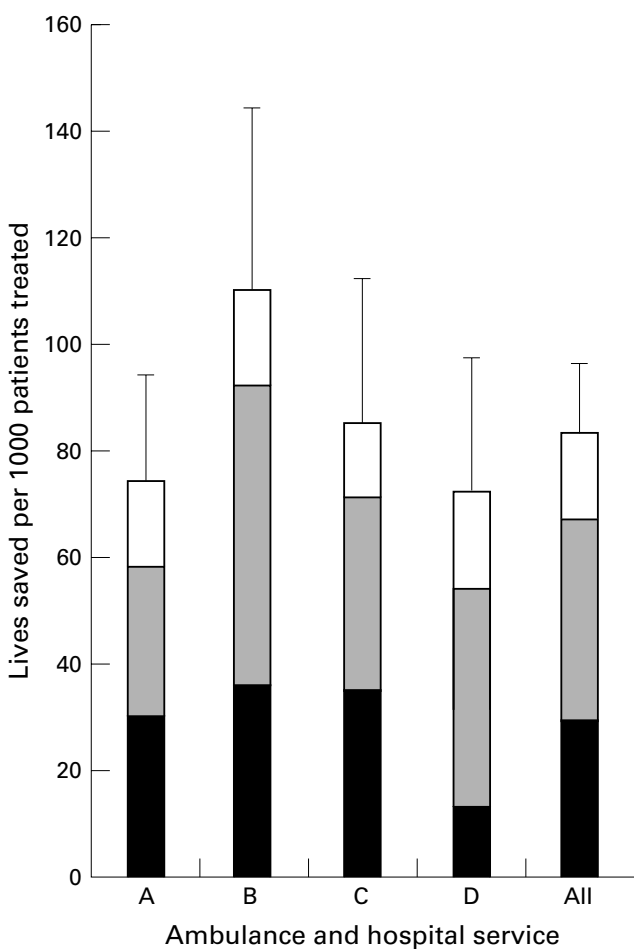

Figure 1 Lives saved/1000 patients treated. Black histograms show lives saved by resuscitation from out of hospital cardiac arrest. Grey histograms show lives saved by resuscitation from in hospital arrest. Clear histograms show lives estimated to have been saved by thrombolytic treatment.

the proportion of patients resuscitated outside hospital was the only case mix variable that differed significantly among the hospitals (table 3 ).

LIVES SAVED/1000 PATIENTS TREATED

Lives saved/1000 patients treated by resuscitation from cardiac arrest performed by the ambulance service, by resuscitation performed in hospital, and by thrombolytic treatment (in all cases given in hospital) are shown in fig 1 . Because well under 1000 cases were treated by each individual hospital or ambulance service, 95\% confidence intervals (CI) of the proportions for each hospital were wide, and there were no significant differences between them. Overall, the lives of 83 patients (95\% CI 70 to 96) per 1000 were saved. Thirty five per cent of the salvage was attributable to out of hospital resuscitation, $46 \%$ to in hospital resuscitation, and $19 \%$ to thrombolytic treatment.

\section{CORRESPONDENCE BETWEEN STUDY AND}

\section{CLINICAL CODING DIAGNOSES}

Of the 640 cases which we had recorded at hospital A, 135 had not received a first coding diagnosis for acute myocardial infarction (ICD 121 or 122). An additional 71 cases had been coded ICD 121 or 122 but had not been recorded or had been rejected for study inclusion. Thus the sensitivity of clinical coding for identification of study cases from the number of cases coded divided by the number identified by the study was $505 / 640$, or $79 \%$. The positive predictive value of the coding diagnosis to predict the study diagnosis was the number of study cases coded divided by the total
Table 5 Coded diagnoses of study patients not coded as acute myocardial infarction

$\begin{array}{lr}\text { Unstable angina } & 64 \\ \text { Other angina } & 8 \\ \text { Myocardial infarction as second code } & 6 \\ \text { Angina as second code } & 3 \\ \text { Chronic IHD } & 8 \\ \text { Cardiac arrest } & 11 \\ \text { Cardiac failure } & 7 \\ \text { Arrhythmia } & 8 \\ \text { Aortic aneurysm } & 2 \\ \text { Cardiomyopathy } & 1 \\ \text { Pericarditis } & 1 \\ \text { Non-cardiac diagnosis } & 5 \\ \text { Records could not matched } & 11 \\ \text { Total } & 135\end{array}$

^Includes one patient who died in accident and emergency and had no hospital number.

IHD, ischaemic heart disease.

number coded, $505 /[505+71]$, or $88 \%$. The hospital fatality rate for the 135 study cases not coded ICD 121 or 122 was $18 \%$, and of the 71 coded cases not included in the study, $28 \%$.

Coded diagnoses of the 135 non-coded cases of acute myocardial infarction included in our study are shown in table 5 . The most common cause of disagreement-applicable to nearly half the cases-was confusion between myocardial infarction and unstable angina. Case notes of 55 of the 71 cases coded as myocardial infarction which we had not included had been reviewed during the study and had been rejected for inclusion. The notes of the other 16 patients had been unobtainable by the end of the study. Reasons for rejection had been acute myocardial infarction or sudden death of patients already in hospital for another reason (excluded by the study protocol), necropsy evidence of recent infarction in patients who appeared clinically to have died from another cause, and cases of prolonged chest pain in which we considered that study criteria had not been met.

\section{Discussion}

Because between two thirds and three quarters of all deaths, comprising one third of all cases of acute myocardial infarction, occur outside hospital, ${ }^{48}$ we considered it important - as far as was possible in these hospital treated patients - to separate the prehospital from the hospital phase of the illness. We therefore considered patient delay in calling for help and patient behaviour in calling their general practitioner or dialling the emergency number as the first variable for audit, followed by performance of the ambulance services in resuscitation from cardiac arrest, and performance of the individual hospitals in delivering resuscitation and thrombolytic treatment.

\section{PATIENT BEHAVIOUR}

Although it is well known that patients who use an emergency number to telephone the ambulance service directly arrive at hospital earlier than those who contact their general practitioner, the difference of nearly three hours was even greater than previously described. ${ }^{511}$ Nearly all of the extra delay in coming under care was attributable to delay by patients who clearly had a lesser sense of urgency, presumably because they had less severe symptoms. ${ }^{12}$ 
The reason why centre A patients were more likely to call the ambulance directly may have been a pilot of the Heart Attack Action! public educational campaign, which had been promulgated through general practitioner surgeries in centre A, but not the other centres, since the beginning of $1995 .^{7}$ The message of Heart Attack Action! was "Chest pain lasting longer than 15 minutes. Call 999 for an ambulance." It appeared that the second part of the message had been acted upon, but the urgency implied by the first part of the message had not.

AMBULANCE PERFORMANCE

Because hospital fatality rates must be determined to a large extent by the proportion of high risk patients which are brought to it by the ambulance service, ambulance performance needs to be considered among the explanatory variables for the assessment of hospital performance. Hospital D, which serves a largely rural area and is situated about 15 miles distant from two other hospitals which were not included in the study, received significantly fewer cases of out of hospital arrest than the other three participating hospitals. This may have contributed to the lower fatality rate at hospital D. The importance of the ambulance in saving lives is emphasised by the fact that 41 (39\%) of the 105 patients successfully resuscitated and discharged from hospital owed their lives primarily to the ambulance service.

HOSPITAL PERFORMANCE

Apart from the difference just noted, case mix - with its expected major effect on outcomes (table 4) - was similar at the four hospitals. Likewise hospital performances in resuscitation, delivery of thrombolytic treatment, and hospital fatality rates (if the differing proportions of out of hospital arrests were excluded) were also similar. The low proportion of hospital arrests verified to have been caused by ventricular fibrillation ( $37 \%$ overall) was surprising, although this figure included all first cardiac arrests, whether resuscitation was attempted or not. Although the proportion of patients given thrombolytic treatment (55\%) corresponded exactly with current guidelines ${ }^{13}$ and $94 \%$ of patients given thrombolysis had the accepted ECG indications, delays to administration were still far from ideal. Only $2 \%$ of patients were treated within the golden hour, during which period thrombolysis-in terms of saving lives - has been estimated to be twice as effective as when given later. ${ }^{10}$ Only half the patients achieved the recommended target for thrombolytic treatment to be started within 90 minutes of calling for help. ${ }^{14}$ Door to needle time, although an important indicator of hospital staff performance, accounted for less than $25 \%$ of the total delay; the median door to needle time of 45 minutes was similar to that reported recently from 15 UK hospitals. ${ }^{11}$ Administration of thrombolysis in the accident and emergency department, as was the practice in hospital A, did not materially alter the hospital delay time compared with administration after direct admission to the coronary care unit, as was the policy in hospital B. The only realistic strategy for substantial reduction in delay appears to be administration of thrombolysis during the prehospital phase.

LIVES SAVED VERSUS CASE FATALITY AS

PERFORMANCE INDICATORS

The present figure of 83 (70-96) lives saved/ 1000 patients treated was higher than that previously reported from $\mathrm{UKHAS}^{5}$ (64 (54-74)). However, lives saved by out of hospital resuscitation were omitted from the previous calculation. Inclusion of ambulance resuscitated cases in the UKHAS results gives a figure of 83 (7591) lives saved, which is the same as the present figure.

Even with the use of similar protocols for case detection and selection, however, hospital fatality in the present survey $(11.5 \%)$ was $20 \%$ lower than in the earlier UKHAS study $(14.2 \%$ when deaths after discharge from hospital were excluded). ${ }^{5}$ We are unable to account for this discrepancy, as strenuous efforts were made in both studies to identify all deaths, and in particular all those that occurred in accident and emergency departments or in tertiary referral centres, to which some patients had been transferred for further investigation or treatment. Although it would not explain the above discrepancy, much of the variation of case fatality between published studies and "official" figures ${ }^{15}$ may reflect differences of definition between clinical coders and auditors on the one hand and clinicians on the other. In hospital A in the present study, sensitivity and positive predictive value for clinical coding to predict study diagnoses were $79 \%$ and $88 \%$, respectively, and both of the omitted groups of patients had fatality rates (18\% and $28 \%)$ which were higher than that which we found in study patients $(13.2 \%)$. It can be calculated that the removal of 135 cases with $18 \%$ fatality and the addition of 71 cases with $28 \%$ fatality would have increased the fatality rate which we found from $13.2 \%$ to $13.9 \%$. Because the numbers of fatal cases added and removed in hospital A were approximately balanced, this difference is small, but the difference may have been larger at the other three hospitals in our study.

As a performance indicator, lived saved $/ 1000$ treated is attractive because it measures the success of treatment rather than its failure. Moreover the numerator can be measured unambiguously as patients who have been resuscitated or treated with thrombolysis can easily be identified. Inevitable disagreements between clinical and coding diagnoses, which we found to involve a large proportion of fatal cases, should not affect calculation of this index unduly, because such cases affect only the denominator and not the numerator of the indicator. "Lives saved" also emphasises the importance of advanced life support-both in and out of hospital-as the cornerstone of treatment for acute myocardial infarction.

LIVES SAVED BY THROMBOLYTIC TREATMENT The indicator does not acknowledge the life saving antithrombotic role of aspirin, which was found in the ISIS-2 trial $^{16}$ to be similar in 
degree to that of streptokinase (about 24/1000 lives saved by aspirin $v$ about $28 / 1000$ saved by streptokinase). Because the use of aspirin is now near universal, we thought it unnecessary to include it in the indicator, but it should be noted that the figure of 16 lives saved/1000 patients treated underestimates the efficacy of thrombolytic treatment when combined with an antithrombotic drug.

Neither does the indicator assess the process of thrombolysis, and in particular delays from onset of symptoms to the start of treatment. Trials comparing different thrombolytic regimens show an important adverse effect of delay. ${ }^{17} 18$ However, this effect was almost abolished-at least for delays of less than six hours-by correction for baseline prognostic variables. ${ }^{18}$ The most reliable method for estimation of the effects of delay comes from meta-analyses of the clinical trials ${ }^{910}$ in which survival after thrombolysis was compared with survival with no treatment.

The fibrinolytic therapy trialists (FTT) collaborative group ${ }^{9}$ concluded that the loss of efficacy with delay in treatment was linear, with an extra 1.6 per 1000 lives lost for each hour of delay. For patients with ST elevation or bundle branch block treated within six hours of onset, a figure of 30 lives saved/1000 treated could be assumed. ${ }^{9}$ Boersma and colleagues, ${ }^{10}$ by adding results from smaller studies of prehospital thrombolysis to the meta-analysis, concluded that loss of efficacy with time was curvilinear, with efficacy almost doubled during the first hour, at 65 (38-93) per 1000 v 37 (20-55), 26 $(14-37)$, and $29(19-40)$ at one to two, two to three, and three to six hours, respectively. Comparison of the FTT estimates with those of Boersma and colleagues shows that differences between the two estimates are essentially confined to the first hour. Calculated differences in efficacy between one to two hours and three to six hours, according to Boersma and colleagues, were little different from the $1.6 / 1000$ per hour estimate of the FTT collaborators, particularly when the wide confidence intervals are taken into account. In the present survey - as in the previous UKHAS study ${ }^{5}$ - only $2 \%$ of treated patients started their treatment within the first hour, so differences in times from onset of symptoms to start of treatment between the four hospitals did not materially affect the overall figure of 30/1000.

The above does not deny the importance of reducing hospital delay in starting thrombolytic treatment to improve the process of care, but results of the meta-analyses do suggest that such an effect on process is unlikely to improve outcomes significantly because the major delay has already occurred. This estimate might need revision if restoration of blood flow to the infarct related coronary artery could be accomplished more quickly than at present. The thrombolytic drug used for most patients in our hospitals - as in the meta-analyse ${ }^{9}{ }^{10}$ was streptokinase. Administration of a more rapidly acting plasminogen activator to a substantial proportion of patients during the prehospital phase and within one hour of onset of symptoms, or primary angioplasty per- formed immediately after arrival at hospital, might make the figure of 30/1000 lives saved an underestimate. If a larger proportion of patients were to come under care earlier, many more lives would also be a saved by resuscitation from cardiac arrest.

THE PRESENT METHOD AS A POSSIBLE MODEL FOR FUTURE AUDIT PROGRAMMES

We believe that the present audit method provides potential advantages over other hospital based methods for audit of acute myocardial infarction. First, by separating patient behaviour in calling for help and ambulance performance in treating out of hospital arrest from hospital management, it gives due weight to the all important prehospital phase of infarction. Second, lives saved/1000 patients, considered in conjunction with delays to coming under care, may provide an alternative to case fatality as a possibly more robust indicator of patient behaviour and ambulance and hospital performance.

This project could not have been performed without the enthusiasm and dedication of the research nurses. I am grateful for the expert secretarial assistance of Mrs Janet Stevens. Supported by a project grant from the British Heart Foundation and by grants from the PPP Medical Trust and the Brighton Heart Support Trust.

\section{Participating centres}

Brighton-Coordinating centre, Royal Sussex County Hospital: RM Norris (honorary consultant cardiologist, study director), $\mathrm{R}$ Vincent (consultant cardiologist), Gaynor Dixon (research sister responsible for coordination and database management), Christopher Edwards (staff nurse)

Eastbourne-Eastbourne District General Hospital: N Sulke (consultant cardiologist), Janet Large (sister).

Hastings-Conquest Hospital: R Wray (consultant cardiologist), Michele Parks, Hayley Coxon (sisters).

Canterbury —Kent and Canterbury Hospital: A Owen (consultant cardiologist), Janet Husk (audit officer).

1 Department of Health. National Service Framework for coronary heart disease. London: Stationery Office, 2000. Full details on $\mathrm{DOH}$ website.

2 Birkhead JS, (on behalf of the Working Group). Health outcome indicators. Myocardial infarction. Report of a working group to the Department of Health. Oxford: National Centre for Health Outcomes Development, 1999.

3 Birkhead JS, Norris R, Quinn T, et al. Acute myocardial infarction. A core dataset for monitoring standards of care. infarction. A core dataset for monitoring standd

4 Norris RM, on behalf of the United Kingdom Heart Attack Study Collaborative Group. Fatality outside hospital from acute coronary events in three British health districts 994-95. BMF̈ 1998;316:1065-70.

5 The United Kingdom Heart Attack Study Collaborative Group. Effect of time from onset to coming under care on fatality of patients with acute myocardial infarction: effect of resuscitation and thrombolytic treatment. Heart 1998; 80:114-20.

6 Norris RM. Sudden cardiac death and acute myocardial infarction in three British health districts. London: British Heart Foundation, 1999

7 Dixon GF, Norris RM, Vincent R. Heart Attack Action! A campaign to increase the community knowledge [abstract] Heart 1996;75:80.

8 Tunstall-Pedoe H, Kuulasmaa K, Amouyel P, et al. Myocardial infarction and coronary deaths in the World Health Organisation MONICA registration project: registration procedures, event rates and case fatality rates in 30 populaprocedures, event rates and case fatality rates in 30 popula-
tions from 21 countries in 4 continents. Circulation tions from 21 coun 
9 Fibrinolytic Therapy Trialists (FTT) Collaborative Group. Indications for fibrinolytic therapy in suspected acute myocardial infarction: collaborative overview of early mortality and major morbidity results from all randomised trials of more than 1000 patients. Lancet 1994;343:311-22.

10 Boersma E, Maas ACP, Simoons ML, et al. Early thrombolytic treatment in acute myocardial infarction: reappraisal of the Golden Hour. Lancet 1996;348:771-5.

11 Birkhead JS. Trends in the provision of thrombolytic treatment 1993-97. Heart 1999;82:438-42.

12 Trent RJ, Rose EL, Adams JN, et al. Delay between the onset of symptoms of acute myocardial infarction and seeking medical assistance is influenced by left ventricular function at presentation. Br Heart $\mathcal{F}$ 1995;73:125-8.

13 European Secondary Prevention Study Group. Translation of clinical trials into practice: a European population-based study on the use of thrombolysis for acute myocardial infarction. Lancet 1996;347:1203-7.
14 Weston CFM, Penny WJ, Julian DG. Guidelines for the early management of patients with myocardial infarction. early management of p

15 NHS Executive. Quality and performance in the NHS. High level performance indicators. London: HMSO, 1999. [Full report on the $\mathrm{DOH}$ website.]

16 ISIS-2 (Second International Study of Infarct Survival) Collaborative Group. Randomised trial of intravenous streptokinase, oral aspirin, both, or neither among 17,187 cases of suspected acute myocardial infarction: ISIS-2. Lancet 1988;ii:349-60.

17 Newby LK, Rutsch WR, Califf RM, et al. Time from symptom onset to treatment and outcomes after thrombolytic therapy. F Am Coll Cardiol 1996;27:1646-55.

18 Chareonthaitawee P, Gibbons RA, Roberts RS, et al. The impact of time to thrombolytic treatment on outcome in patients with acute myocardial infarction. Heart $2000 \cdot 84$ : patients with acute myocardial infarction. Heart 2000;84:

\section{IMAGES IN CARDIOLOGY}

\section{Bilateral Winslow's pathways}

A 50 year old man with a history of familial hypercholesterolaemia was admitted because of bilateral intermittent claudication of both legs and chest pain. An abdominal aortogram revealed total occlusion of the infrarenal aorta (below). Cardiac catheterisation revealed severe triple vessel disease with normal left ventricular function. Selective angiography of the bilateral internal thoracic arteries documented rich anastomoses between the superior and inferior epigastric arteries with retrograde flow to the ipsilateral external iliac arteries (Winslow's pathway) (right). In this case, these findings were especially important in order to avoid the risk of acutely ischaemic limbs, because the internal thoracic arteries would have been used for coronary artery bypass grafting.

Both aorto-bifemoral grafting and coronary artery bypass grafting using bilateral internal mammary arteries and left radial artery were simultaneously undergone without complication.
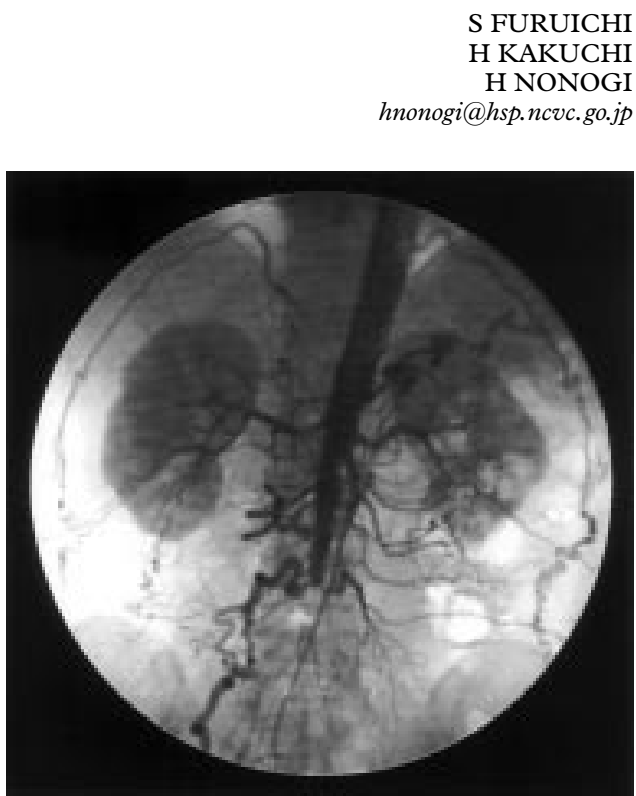
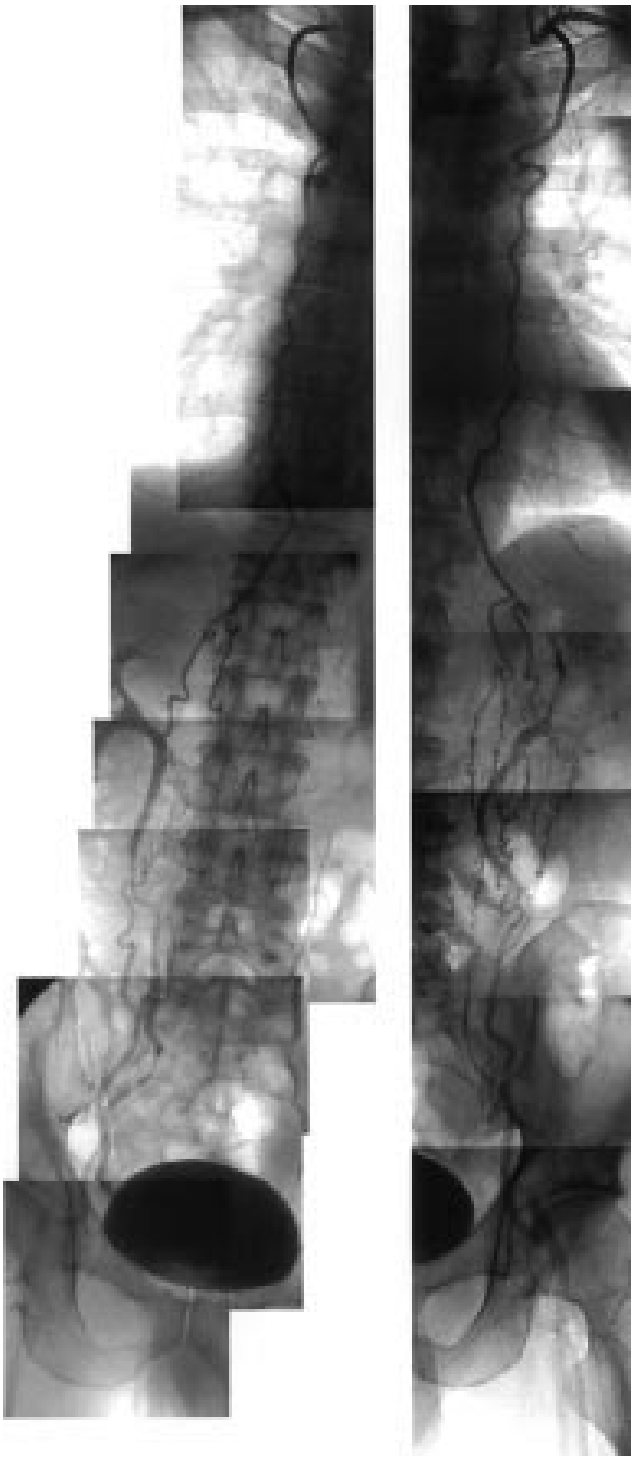